\title{
CONTINUOUS USE OF STUDENT RESPONSE SYSTEMS IN UNIVERSITY CLASSES: A QUANTITATIVE STUDY OF STUDENT RESPONSE RATES
}

\author{
Paul Lam, Carmen K. M. Lau, Kevin Wong and Chi Him Chan \\ The Chinese University of Hong Kong, Hong Kong
}

\begin{abstract}
Student Response Systems (SRS) allow all students to participate in the classroom using their own devices. While it is an effective tool for promoting active participation and classroom interaction, previous studies argue that overuse of the technology can pose a problem of student disengagement. This paper reports on a quantitative study of the relationship between the number of SRS questions disseminated and the number of students' responses, drawing on data from a locally-developed SRS that was used campus-wide between 2012 and 2015 at The Chinese University of Hong Kong. Although the number of questions per session varied among different disciplines, likely due to the differences in learning objectives, our results show that student responses were generally stable with virtually no significant drop at the end of the lessons regardless of the number of questions asked. However, other factors may have affected the number of student responses. Our results suggest that continuous use of the technology does not lower student participation, but the design of learning activities may influence the effectiveness of SRS.
\end{abstract}

\section{KEYWORDS}

Student Response System, Student Engagement

\section{INTRODUCTION}

Student Response Systems (SRS), also known as Classroom Response Systems (CRS) or Audience Response Systems (ARS), are a set of hardware and software that allows teachers to pose different types of questions to students in class. Students can submit their answers using provided handheld devices or even their own mobile phones or laptop computers through a wireless network. Teachers can collect and analyse student responses instantly and convert them into different statistics (Kay and LeSage, 2009). Without the use of SRS, question and answer activities in the classroom are usually characterised by the teacher calling upon one student at a 
IADIS International Journal on WWW/Internet

time to respond. In this setting, only a small number of students answer questions consistently, and the rest of the class is neglected and is subjected to passive listening (Fitch, 2004; Narayan et al., 1990). This technological innovation provides opportunities for all students to respond to teachers simultaneously in class, and teachers can immediately receive and analyse students' responses.

The main benefit of SRS is to help facilitate active learning pedagogies (Martyn, 2007), which seek to engage students in the learning process and stimulate their thinking through the use of learning activities (Prince, 2004). SRS facilitates various learning activities that motivate students to participate in class, such as discussion among students (Boscardin and Penuel, 2012), formative assessments (Goldstein, 2015) and in-class polling (Krabill, 2015). Furthermore, by providing anonymity for students, SRS encourages the participation of introverted or anxious students (Stowell and Nelson, 2007; Stowell et al., 2010; Florenthal, 2018) by protecting them from the embarrassment of making incorrect responses (Filer, 2010; Florenthal, 2018). Additionally, SRS stimulates students' thinking and active participation since every student is given an opportunity to respond to the teacher's questions, and in responding to the questions, students need to process information independently and commit to an answer (Filer, 2010). Finally, SRS also refreshes students' attention span in class in order to keep students actively engaged. Research shows that students' attention dramatically decreases after 20 minutes in a lecture (Jackson et al., 2005; Kay and LeSage, 2008), thus reducing retention of the learning material presented. There is a need to give students a break during long lectures, and SRS can provide different learning activities that serve as a break to refresh students' attention (Kay and Lesage, 2009). All of these advantages contribute to the facilitation of active learning pedagogies by increasing interactivity and encouraging a more dynamic classroom. Indeed, Hunsu et al. (2016) examined empirical studies on the use of SRS and confirmed the positive effects of SRS on students' engagement and participation, attendance, and self-efficacy across different subjects.

With the vision of promoting active learning, The Chinese University of Hong Kong developed an SRS, uReply, for campus-wide use. uReply is a cloud-based classroom communication system with an aim to promote a campus-wide adoption of active and student-oriented learning in all disciplines by fostering classroom communication and interaction. Hence, uReply is designed with the flexibility to address the needs of different students from different disciplines. For example, uReply supports a variety of question types, including multiple-choice questions, text questions without word limits, Likert scale, fill-in-the-blank and direct messages. It is also easy to use as teachers can ask a question by simply typing the question on the spot or picking ready-made question items from his/her personal question bank. Students can also easily submit their answers via their internetconnected mobile devices or laptop computers. Student responses are by default anonymous unless the teacher requires students to enter their names or student ID numbers when they submit their responses. Additionally, all activities are automatically recorded into the dataset for future use. Hence, uReply benefits teachers from different disciplines with different teaching needs and different levels of technical background knowledge. By January 2019, there were more than two million page-views, 18,000 entries in the question bank and more than 1,600 teacher accounts created in the system at The Chinese University of Hong Kong alone.

However, simply installing and using the SRS in a classroom does not automatically produce these advantages. The potential of SRS has to be realised by careful planning of classroom activities and good pedagogical practices. Strategies and tips on using SRS in the classroom often warn against the potential danger of overusing the new technology. For example, 


\section{CONTINUOUS USE OF STUDENT RESPONSE SYSTEMS IN UNIVERSITY CLASSES:}

A QUANTITATIVE STUDY OF STUDENT RESPONSE RATES

Robertson (2000) believes that students' enthusiasm will fade if they are presented with question after question. Martyn (2007) also advises against asking too many questions. Cain and Robinson (2008) believe that the overuse of the system can lead to students' burnout and apathy. Regarding the adequate number of questions, Premkumar (2009) suggests that three to four questions in a 60-minute lecture would be adequate. Similarly, Carnaghan (2011) prefers no more than four questions per hour of class. These warnings and tips suggest that continuously posing questions through SRS may diminish the benefits of the technology by driving students away. This adverse effect is thought to be observed by a decrease in the number of student responses.

Regarding this problem, the current study investigated whether students' participation in class decreases if teachers continue asking questions through SRS. This idea can be formulated into a research hypothesis: if the number of questions teachers ask increases, the number of student responses will decrease. A quantitative study on the dataset of uReply examined the quantity of questions teachers posed per session and the number of student responses. The research results disproved the research hypothesis, showing that there was no significant decrease in student responses as teachers asked more questions. However, our research result also showed the quantity of questions varied between classes, and the number of students' responses also varied between different questions. A preliminary observation of the disciplinary distribution of the sessions may help us understand different factors for such variation and provide insights for the pedagogical use of the SRS.

\section{METHODOLOGY}

\subsection{Data Collection}

The research data of this study came from the cloud-based SRS, uReply, that was developed and has been in use campus-wide since 2012 at The Chinese University of Hong Kong. The researchers retrieved from the system the raw usage data recorded over a 3-year period from May 2012 to May 2015. The raw usage data contains 5370 sessions. One session in the dataset stands for a session of class activity that can last for a whole lecture, which is around two to three hours. Teachers generally start a uReply session at the beginning of their lecture and end the session when their lecture ends. Teachers can ask as many questions as they like in a single session. A total of 606 teacher users from all eight faculties and different teaching units of The Chinese University of Hong Kong contributed to the dataset. Hence, the data collected was not limited to any particular discipline.

\subsection{Data Cleaning}

Among these 5370 sessions, two types of sessions were excluded from our research: the sessions that did not record real classroom use and the sessions that contained data invalid for our research. The former type of sessions included 1) sessions created by our development team when they built and tested the system; 2) teachers' trial usage sessions; and 3) sessions without accurate information about the course, the teachers or the students. The latter type of sessions included 4) sessions that were used across multiple lectures; 5) sessions that contained only one question; and 6) session groups that contained too few sessions for valid analysis, especially on 
IADIS International Journal on WWW/Internet

sessions over 20 questions. The refinement process of the dataset was divided into five stages as listed below.

In the first stage, sessions from non-teacher accounts, including team project users and developers were deleted. A total of 89 user accounts and 1911 sessions were deleted in this stage. In the second stage, 338 sessions without accurate information on the identity of teacher users or session ID were deleted because they could not be proven to show actual classroom usage. In the third stage, we identified and deleted sessions of trial usage. Trial usage sessions were identified by the number of question respondents in each session. Although uReply can be used in a class with as few as two students, we believe that the teachers would not create too many respondents in their trial usage sessions, hence, trial usage sessions were expected to contain a fewer number of respondents. With this hypothesis, we calculated the rate of real uses on five groups of sessions that had two to six respondents respectively to determine the margin for our study. We randomly selected 30 sessions from each of these five groups as samples. All the questions and answers in these 150 sessions were examined to judge whether they were trial usage or not, but some sessions were still unable to be classified because there was no clear evidence. Next, we calculated the rate of real cases (TRUE session / (No. of sessions - undefined sessions) for each of the five groups. Table 1 shows the results of this analysis. In groups of sessions that had five or more respondents, more than $90 \%$ of the sessions were identifiable real classroom uses. We determined that $90 \%$ could be the acceptable margin for our study to balance data quality and data quantity. Therefore, we deleted all the sessions that had fewer than five respondents. In this stage, 686 sessions were deleted.

Table 1. Analysis of identifiable real classroom usage for sessions containing 2-6 respondents

\begin{tabular}{|c|c|c|c|c|c|}
\hline No. of Respondents & 2 & 3 & 4 & 5 & 6 \\
\hline No. of Sessions & 30 & 30 & 30 & 30 & 30 \\
\hline Real-usage Sessions & 13 & 18 & 22 & 24 & 27 \\
\hline Trial-usage Sessions & 12 & 5 & 3 & 2 & 2 \\
\hline Undefined Sessions $*$ & 5 & 7 & 5 & 4 & 1 \\
\hline Rate of Real Cases $(\%)$ & $52.00 \%$ & $78.26 \%$ & $88.00 \%$ & $\mathbf{9 2 . 3 1 \%}$ & $\mathbf{9 3 . 1 0 \%}$ \\
\hline
\end{tabular}

In the fourth stage, sessions that were used across multiple lectures were deleted. uReply allows users to reuse the session they created. However, when a session is reused in another lecture, the number of respondents and questions differ from the previous use. Therefore, the data of reused sessions was not valid for analysis, so we also deleted these 571 sessions. Finally, the remaining 1864 sessions were grouped according to the number of questions asked in each session. The group of sessions that contained only one question and groups that contained too few sessions, which mainly included sessions with more than 20 questions, were excluded. We excluded the former because there would be no change in student response rate if a session contained only one question and the latter because the samples were not representative for a valid study. In this stage, 852 sessions were excluded. The remaining 1012 sessions were eligible for our analysis. 
Table 2. The data cleaning process

\begin{tabular}{|c|c|c|}
\hline & Sessions excluded & Sessions remaining \\
\hline Total number of sessions & & 5370 \\
\hline Sessions from non-teaching accounts & 1911 & 3459 \\
\hline Sessions without accurate information & 338 & 3121 \\
\hline Sessions with fewer than 5 respondents & 686 & 2435 \\
\hline Sessions used across multiple lectures & 571 & 1864 \\
\hline $\begin{array}{c}\text { Sessions containing only 1 question and } \\
\text { over 20 questions }\end{array}$ & 852 & 1012 \\
\hline Total number of sessions for analysis & & 1012 \\
\hline
\end{tabular}

\subsection{Data Analysis}

After the data cleaning process, the 1012 sessions were grouped according to the number of questions each session contained. The number of questions in these sessions ranged from as few as two questions to as many as twenty. Next, the data was subjected to five types of analysis. First, an analysis was conducted to determine any statistically significant differences in student responses between the beginning and the end of a session. Because the response of a single question may rise or fall drastically due to various reasons, the analysis avoided using solely the first and the last item for measurement except for the group of sessions containing only two to four questions. Therefore, we defined the "beginning" and the "end" portion and illustrated the number of student responses for both portions. Furthermore, a statistic on the group sessions provided us an overview of teachers' preference on the number of questions per session. After that, t-test analysis on each pair for the beginning and the end portion for groups that consisted of more than 20 sessions allowed us to examine whether there were statistically significant differences between the number of responses for the beginning and end portions of the sessions. In addition, investigation on the number of students responses for each question in each group of sessions provided details on the changes in numbers of students responses. Finally, the sessions were mapped into faculties according to the affiliations provided by the teacher users to investigate if disciplinary differences affected the use of uReply.

\section{RESULTS}

We first investigated whether there were significant differences in the student responses when the number of questions increased. Table 3 below demonstrates the number of student responses for the beginning and the end portions of each group of sessions. The columns on the left illustrate the number of responses received in the beginning portions, including the minimum value, the maximum value and the mean; the columns on the right illustrate the number of responses received at the end of the sessions, including the minimum value, maximum value and the mean. The results show that the numbers of responses collected in the beginning and at the end of the class were close, indicating that students continued responding to the teacher while the number of questions increased. For example, in sessions that contained seven questions, a mean of 1406 responses for each question were collected in the beginning portion (the first two questions) compared to around 1360 at the end portion (the last two questions). 
IADIS International Journal on WWW/Internet

Table 3. Comparison of the number of student responses between the beginning and the end portions

\begin{tabular}{|c|c|c|c|c|c|c|c|c|c|c|}
\hline \multirow{2}{*}{$\begin{array}{c}\text { No. of } \\
\text { Questions } \\
\text { in a } \\
\text { Session }\end{array}$} & \multirow{2}{*}{$\begin{array}{c}\text { No. of } \\
\text { Sessions }\end{array}$} & \multirow{2}{*}{$\begin{array}{l}\text { Question } \\
\text { (s) in } \\
\text { portion }\end{array}$} & \multicolumn{4}{|c|}{ Beginning portion } & \multicolumn{4}{|c|}{ End portion } \\
\hline & & & Min & Max & Mean & SD & Min & Max & Mean & SD \\
\hline 2 & 283 & 1 & - & - & 9121 & - & - & - & 9043 & - \\
\hline 3 & 198 & 1 & - & - & 5585 & - & - & - & 5404 & - \\
\hline 4 & 145 & 1 & - & - & 4039 & - & - & - & 4045 & - \\
\hline 5 & 115 & 2 & 3082 & 3181 & 3131.5 & 70.0 & 3013 & 3035 & 3024 & 15.6 \\
\hline 6 & 53 & 2 & 1286 & 1367 & 1326.5 & 57.3 & 1380 & 1454 & 1417 & 52.3 \\
\hline 7 & 56 & 2 & 1366 & 1446 & 1406 & 56.6 & 1329 & 1392 & 1360.5 & 44.5 \\
\hline 8 & 44 & 2 & 1752 & 1892 & 1822 & 99.0 & 1493 & 1563 & 1528 & 49.5 \\
\hline 9 & 28 & 3 & 545 & 571 & 558 & 13 & 519 & 541 & 531 & 11.1 \\
\hline 10 & 39 & 3 & 1373 & 1503 & 1438.7 & 65.0 & 1388 & 1408 & 1400.7 & 11.0 \\
\hline 11 & 11 & 3 & 378 & 421 & 392.7 & 24.5 & 352 & 386 & 366.3 & 17.6 \\
\hline 12 & 4 & 3 & 160 & 177 & 168.7 & 8.5 & 174 & 201 & 183.3 & 15.3 \\
\hline 13 & 5 & 4 & 207 & 250 & 228 & 19.9 & 193 & 214 & 206 & 9.8 \\
\hline 14 & 8 & 4 & 263 & 283 & 270.8 & 9.0 & 212 & 235 & 223.8 & 12.4 \\
\hline 15 & 4 & 4 & 159 & 168 & 163.8 & 3.8 & 148 & 158 & 152 & 4.5 \\
\hline 16 & 12 & 4 & 656 & 690 & 679.8 & 16.0 & 658 & 691 & 673.3 & 13.6 \\
\hline 17 & 3 & 5 & 125 & 145 & 138.8 & 8.0 & 124 & 142 & 134.4 & 7.4 \\
\hline 20 & 4 & 5 & 199 & 218 & 208.6 & 6.9 & 131 & 220 & 198.8 & 38.0 \\
\hline
\end{tabular}

From the first two columns of Table 3, it can also be observed that teachers tended to ask fewer than ten questions in a single session. Figure 1 below shows the distribution of groups of sessions according to the number of questions. Sessions containing only two questions made up $28 \%$ of the sessions, while $73 \%$ of sessions contained two to five questions. Sessions containing six to ten questions comprised another $22 \%$. These sessions made up a total of $95 \%$ of all sessions. Because of the small number of sessions containing more than ten questions, the average number of responses for each question in these sessions rose and fell sharply, as shown in Figures 4 and 5. However, a significant trend of decreasing participation from the beginning to the end portion was not notable in most of these sessions. Rather, the number of student responses varied between questions, suggesting that there were other factors affecting the number of student responses. 
CONTINUOUS USE OF STUDENT RESPONSE SYSTEMS IN UNIVERSITY CLASSES: A QUANTITATIVE STUDY OF STUDENT RESPONSE RATES

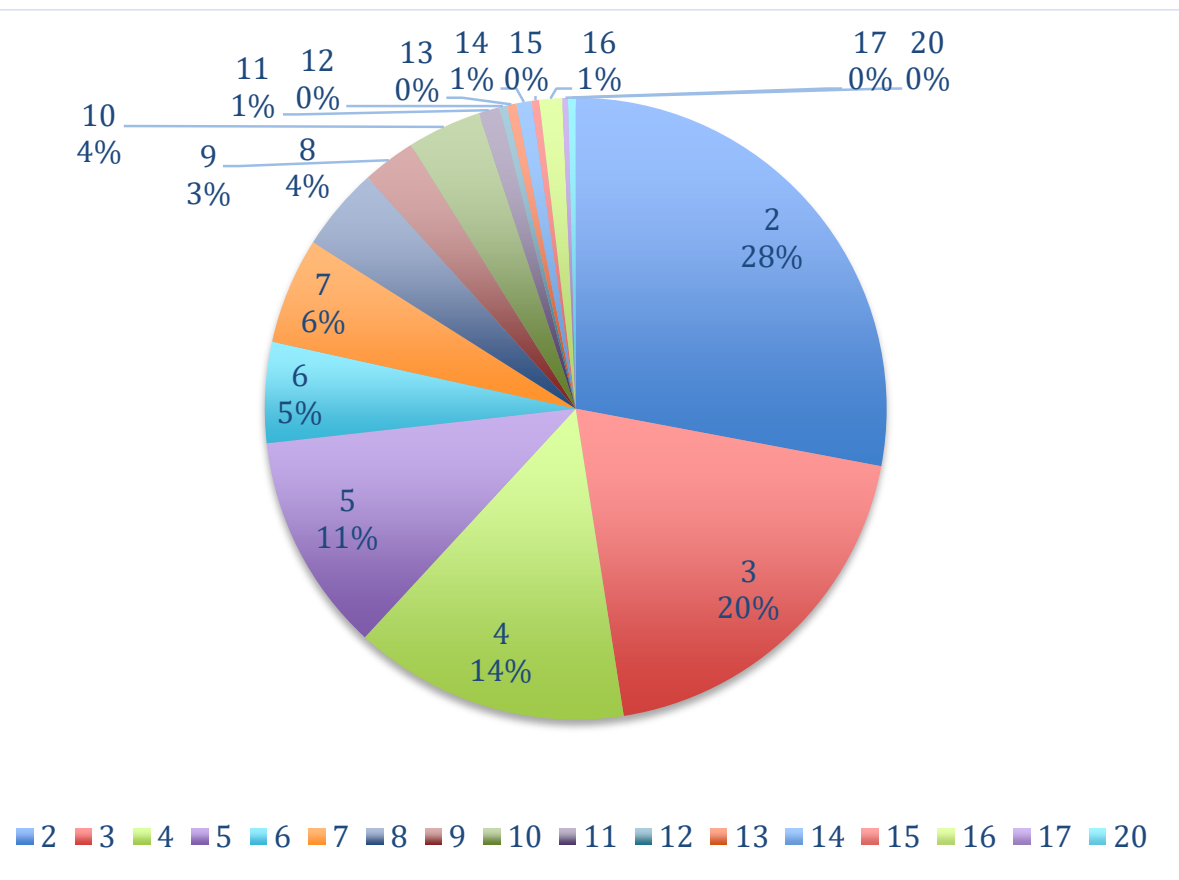

Figure 1. Distribution of sessions according to the number of questions

Table 4. T-test analysis to pairs of the beginning and the end portions for each group

\begin{tabular}{|l|l|l|l|l|}
\hline $\begin{array}{l}\text { No. of Questions } \\
\text { in Sessions }\end{array}$ & $\begin{array}{l}\text { No. of } \\
\text { Sessions }\end{array}$ & $\begin{array}{l}\text { T-Test } \\
\text { Result }\end{array}$ & $\begin{array}{l}\text { Range } \\
\text { (Total Response) }\end{array}$ & Mean \pm SD \\
\hline 2 & 283 & 0.677 & $9043-9121$ & $9082 \pm 55.2$ \\
\hline 3 & 198 & 0.397 & $5404-5670$ & $5627.5 \pm 135.9$ \\
\hline 4 & 145 & 0.970 & $4039-4251$ & $4146.3 \pm 120.4$ \\
\hline 5 & 115 & 0.195 & $3013-3181$ & $3082.6 \pm 65.5$ \\
\hline 6 & 53 & 0.102 & $1286-1462$ & $1382.3 \pm 66.9$ \\
\hline 7 & 56 & 0.375 & $1329-1467$ & $1389.9 \pm 52.1$ \\
\hline 8 & 44 & $\mathbf{0 . 0 3 2}$ & $1493-1892$ & $1654 \pm 149.5$ \\
\hline 9 & 28 & 0.235 & $519-571$ & $545.2 \pm 16.4$ \\
\hline 10 & 39 & 0.437 & $1373-1503$ & $1424.7 \pm 38.8$ \\
\hline $11^{*}$ & 11 & -- & $329-421$ & $370.3 \pm 24.3$ \\
\hline $12^{*}$ & 4 & -- & $160-201$ & $172.7 \pm 10.4$ \\
\hline $13^{*}$ & 5 & -- & $193-250$ & $214.8 \pm 14.8$ \\
\hline $14^{*}$ & 8 & -- & $205-283$ & $250.0 \pm 25.4$ \\
\hline $15^{*}$ & 4 & -- & $147-168$ & $159.5 \pm 7.2$ \\
\hline $16^{*}$ & 12 & -- & $634-710$ & $673.5 \pm 21.5$ \\
\hline $17^{*}$ & 3 & -- & $124-147$ & $139.1 \pm 6.9$ \\
\hline $20^{*}$ & 4 & -- & $131-223$ & $211 \pm 19.8$ \\
\hline & & & & \\
\hline
\end{tabular}


IADIS International Journal on WWW/Internet

Table 4 shows the results of t-tests to each pair for the beginning and the end portion for groups that consisted of more than 20 sessions. Most beginning and end portions of the sessions did not show statistically significant differences (set at .05) in terms of the number of responses collected, except the group of sessions containing eight questions. It can be further observed from Figure 3 that the average number of student responses for the group of sessions containing eight questions reached its peak on the $2^{\text {nd }}$ question and started to decrease from the $3^{\text {rd }}$ question to the $5^{\text {th }}$ question before stabilising. A similar phenomenon of a sudden decrease immediately after the beginning portion of the sessions was also observed in the group of sessions containing thirteen questions.

Figures 2-5 below show the average number of responses to each question for each group. Figure 2 plots the sessions with two to five questions; Figure 3 plots the sessions with six to ten questions; Figure 4 plots the sessions with eleven to fifteen questions; and figure 5 plots the sessions with sixteen, seventeen and twenty questions.

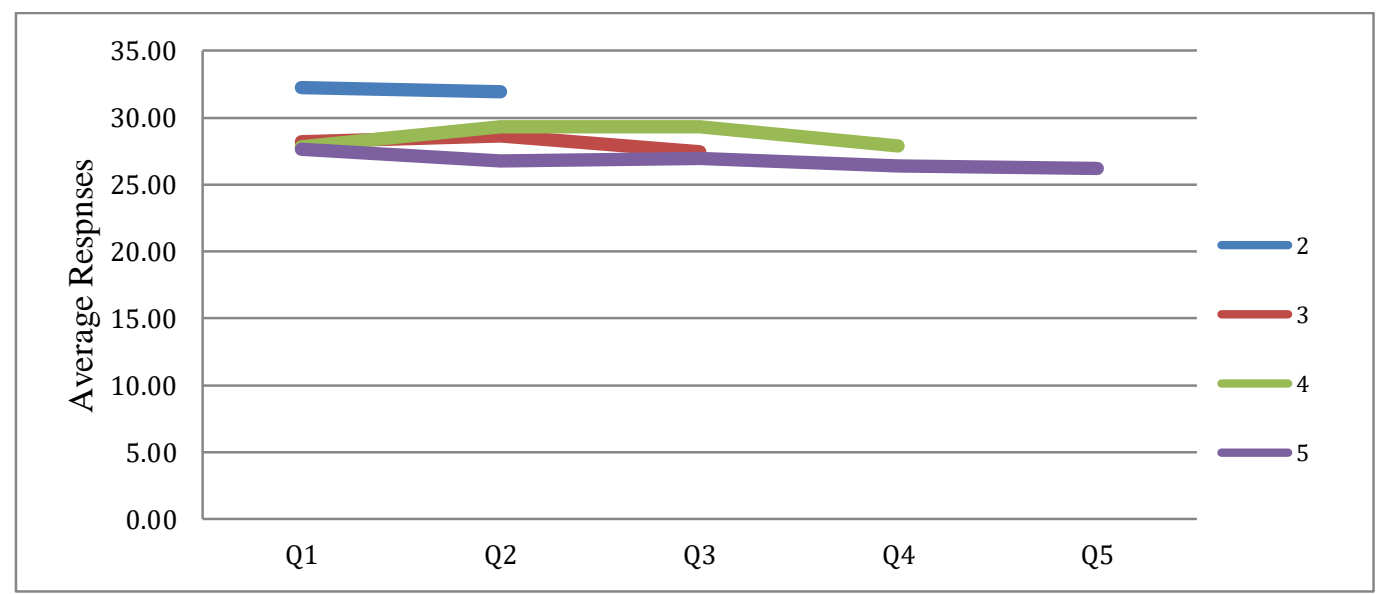

Figure 2. Average responses of each question for sessions with 2 to 5 questions

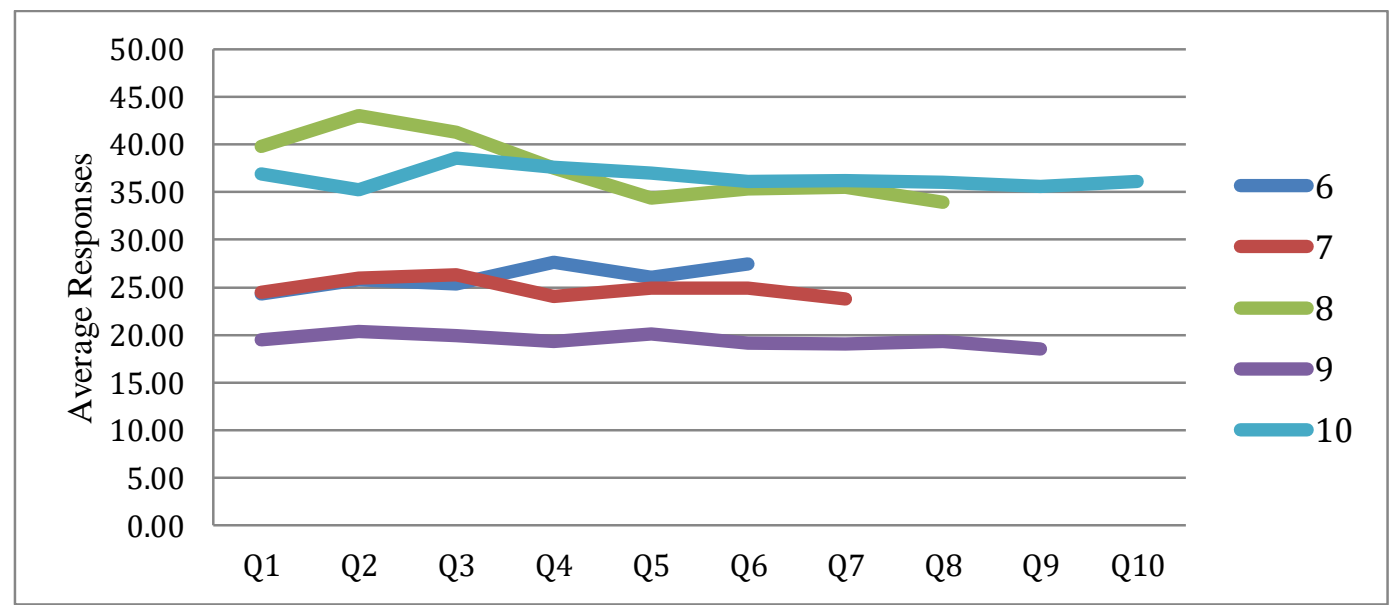

Figure 3. Average responses of each question for sessions with 6 to 10 questions 


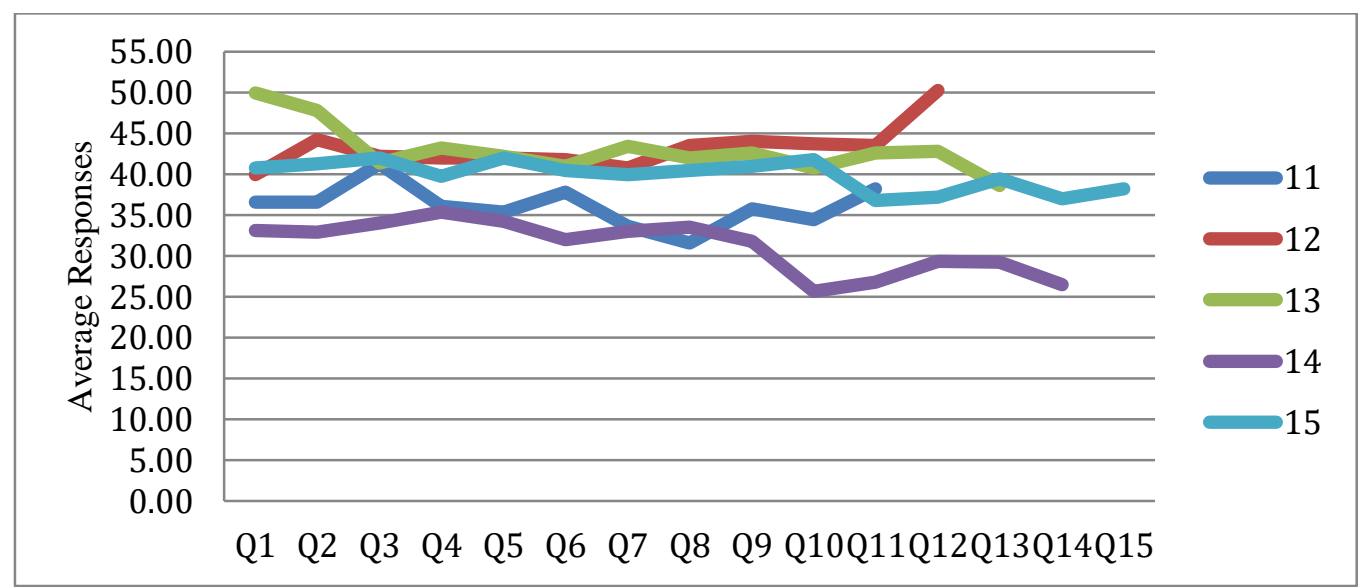

Figure 4. Average responses of each question for sessions with 11 to 15 questions

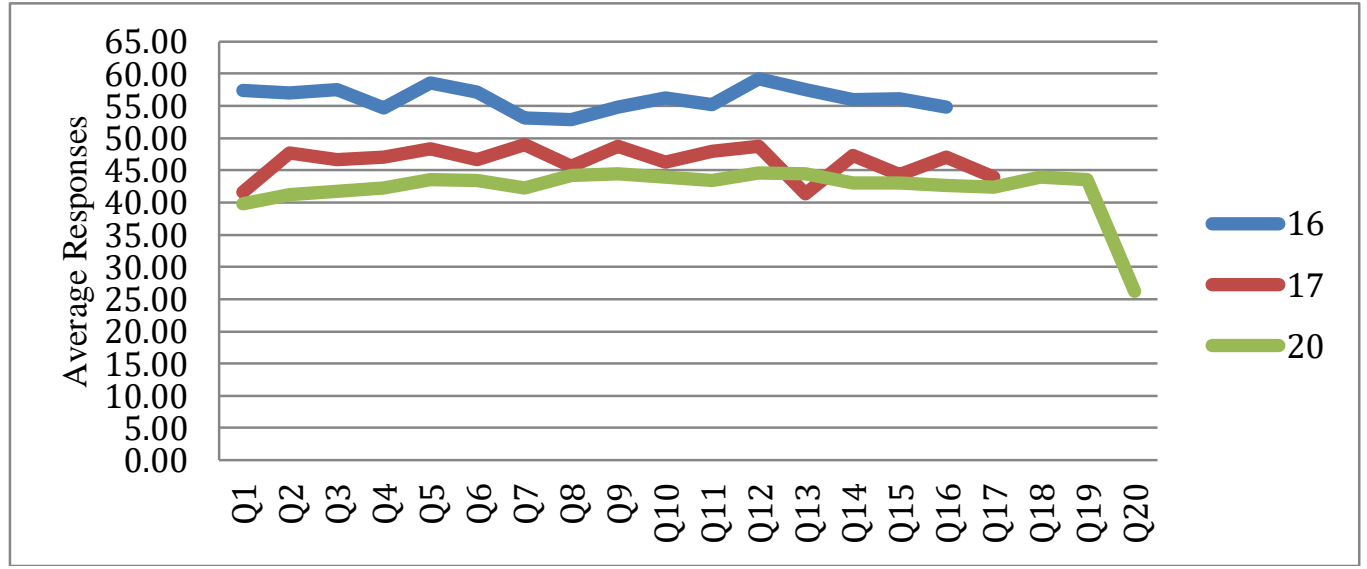

Figure 5. Average responses of each question for sessions with 16, 17 and 20 questions

It should be noted that there was a sudden drop in average responses for the last question in the group of sessions containing 20 questions. It is because there were only four sessions in this group. A significant drop in responses in a single session affects the whole statistic. The sudden drop in response, in fact, occurred only in session no. 1522. In this session, the first nineteen questions were multiple-choice questions, but the last question required students to respond in text form. The change of the question format was probably the cause of the decrease in the number of student responses.

To further investigate the variations of the average session lengths among different disciplines, the sessions were mapped into different faculties with reference to the affiliations provided by the teacher users for observation of disciplinary differences. Among the 1012 sessions, 959 sessions could be identified as sessions for classes provided by various faculties. The 53 sessions left were from courses, seminars, or workshops provided by different units of the university, such as the general education courses and activities provided by the library and museums. These 959 sessions contained a total number of 4675 questions. The following table summarises the number of sessions and the total number of questions contained in all sessions. 
IADIS International Journal on WWW/Internet

Table 5. Average number of questions per session for different faculties

\begin{tabular}{|l|l|l|l|}
\hline & No. of Session & Total no. of Questions & Average no. of Questions per Session \\
\hline Total & 959 & 4675 & \\
\hline Faculty A & 126 & 619 & 4.87486966 \\
\hline Faculty B & 213 & 960 & 4.91269841 \\
\hline Faculty C & 29 & 120 & 4.50704225 \\
\hline Faculty D & 57 & 222 & 4.13793103 \\
\hline Faculty E & 50 & 163 & 3.89473684 \\
\hline Faculty F & 183 & 1192 & 3.26 \\
\hline Faculty G & 104 & 535 & 6.5136612 \\
\hline Faculty H & 197 & 864 & 5.14423077 \\
\hline
\end{tabular}

As illustrated in the above table, the number of sessions varied among faculties. Although the data have not been weighed against the size and the number of courses provided by different faculties, it is evident that uReply was more commonly adopted in some faculties than others, ranging from below 29 to over 200 sessions.

Furthermore, the average number of questions per session also varied among different faculties. As shown in Table 5, the average number of questions per session varied from three to six, and the overall average number of questions was 4.87 . While the wide range of the number of questions per session hints that different disciplines used uReply for different kinds of learning activities, the range also agrees with our observation in Figure 1 that most of the sessions contained only two to five questions.

A closer look at the data reveals that faculty F owned a total of $19 \%(183 / 959)$ of all sessions, but for sessions containing ten or more questions, faculty F occupied $41 \%(26 / 64)$. On the contrary, all 50 sessions of faculty E contained only two to six questions (two: $34 \%$; three: $26 \%$; four: $24 \%$; five: $12 \%$; six: $4 \%$ ). These observations suggest that disciplinary differences affected the average number of questions per session and some disciplines especially favoured sessions with two questions. Not only did the average number of questions per session vary, but also the number of sessions varied a great deal among faculties.

\section{DISCUSSION}

There are five significant observations from our research. First, there were no significant drops in the student responses with an increasing number of questions. Our finding disproves the hypothesis that "if the number of questions teachers ask increases, the number of student responses would decrease". Instead, it shows that the student response rate for SRS was more constant than expected. For teachers concerned that asking too many questions may drive students away, the result of this research is a relief.

Second, teachers often favoured a session containing fewer questions. The sessions containing questions ranging from two to five occupied $73 \%$ of all sessions, and an additional $22 \%$ of sessions contained six to ten questions. That means a total of $95 \%$ of sessions contained ten or fewer questions. An average number of 4.84 questions for all sessions also shows that teachers often favoured fewer questions in a session. Since the number of student responses mostly remained stable in these sessions, as shown in Figures 2 and 3, the issue of losing students' participation and engagement was minimal for most of the sessions. Given that a 


\section{CONTINUOUS USE OF STUDENT RESPONSE SYSTEMS IN UNIVERSITY CLASSES:}

A QUANTITATIVE STUDY OF STUDENT RESPONSE RATES

normal session for a lecture usually last around 1.5 hours, our result suggests that on average, teachers use less questions than the suggested three to four questions per hour (Premkumar 2009; Carnaghan 2011).

Third, the average number of responses might have also been affected by different factors. A session containing 20 questions, session 1522, received a sudden drop of response in the $20^{\text {th }}$ question, which was an open-text question, after 19 multiple-choice questions. Previous research suggests that multiple-choice questions are easier for students because they allow some test-wise strategies, such as response elimination strategy. On the contrary, the constructive response questions that require students to produce text may generate test anxiety (Martinez, 1999). Hence, question format would be an influential factor for the number of student responses. Furthermore, Figure 3 also shows that the groups of sessions containing eight and ten questions experienced a more considerable change in the average number of responses at the beginning of the sessions, which might have been due to issues related to time management. A detailed investigation of the time when a question is asked, the time allowed for students to answer and the question formats for each question being asked may further identify the factors influencing the change in the student response and provide insights for better use of SRS.

Fourth, we would like to stress that the study should not be interpreted as promoting asking as many questions as possible when using SRS. The overall statistics, as well as the analysis of faculty-specific usage, indicate that most teachers asked three to six questions in their classes. This study was only possible because of the vast amount of data we collected that included enough of the less common cases.

Fifth, similarly, we should be warned not to over-simplify the findings in the study to arrive at any single typical usage of SRS. On the contrary, as illustrated by the fact that the number of sessions and the average number of questions varied among disciplines (Table 5), the findings honoured such variance. This point of view echoes a previous meta-analysis on SRS research by Good (2013) which reported differences in the use of SRS in a variety of courses across disciplines. Previous teaching cases in the literature have documented how SRS can provide different learning activities for a range of learning objectives. For example, SRS can be employed to give quick tests with a large number of questions to assess students' understanding of the content or to stimulate students' thinking and encourage discussion through a few controversial questions (Wade, 2015). The former may be more suitable for disciplines that are content-based and the latter may be more suitable for disciplines that aim at fostering students' critical thinking.

\section{LIMITATIONS AND FUTURE WORK}

There are a few limitations regarding this research. First, since the total number of students in each session is unknown, it is hard to estimate the student engagement rate because the total response rate cannot be calculated. Due to this limitation, this research can only show that students who participated at the beginning of the session continued to respond to the teacher throughout the whole session. Second, the study cannot exclude the possibility that student responses were compulsory in class. For example, it is reported that some teachers may use SRS to take attendance (Kay and LeSage, 2009; Hunsu et al., 2016) as there is a function in uReply for teachers to collect registered students responses. Under this function, students have to provide their names or student IDs along with their answers. Because teachers may use these 
IADIS International Journal on WWW/Internet

responses as evidence of students' attendance, students may feel obliged to respond. Further research that separates the anonymous and registered student responses and focuses only on anonymous data may exclude such a possibility. Third, the current study uses the data from the early stage of implementation of this system, hence the data sample is limited to a single university. With the use of uReply extending to other universities in Hong Kong, future studies on the uReply dataset may include samples from different universities through cooperative efforts.

The current study also observes that different factors may affect the quantity of student responses. As seen from the example above, regarding the forms and types of questions, multiple-choice may receive more responses than text questions (Martinez, 1999; Wong et al., 2018). Previous research also speculates that other elements such as the difficulty level of the questions (Carnaghan, 2007), the time allowed for students to respond (Wang et al., 2018) and the type of activities in the classroom may also affect students' response rate. Prior research also suggests that using SRS for competition and games may receive a more positive reception (Wang et al., 2018; Newland and Black, 2019). Therefore, future research that focuses on how teachers design the sessions with a high SRS response rate may reveal positive teaching practices that increase students' participation and engagement.

As an SRS adopted campus-wide in a number of universities in Hong Kong, the database of uReply has the potential to identify SRS user behaviours within different contexts, such as different levels, disciplines and uses. A comparative study on the use of a single SRS across disciplines may help us identify challenges for using SRS in different disciplines and provide insights for improving the SRS. Future research on the uReply database may also focus on how teachers from different disciplines make different use of the system. Such research can help us identify good practices and explore new uses of SRS in different educational settings.

\section{REFERENCES}

Boscardin, C. and Penuel, W. 2012. Exploring benefits of audience-response systems on learning: A review of the literature. Academic Psychiatry, 36(5), 401-407.

Cain, J. and Robinson, E. 2008. A primer on audience response systems: current applications and future considerations. American Journal of Pharmaceutical Education, 72(4), 1-6.

Carnaghan, C and Webb, A. 2007. Investigating the Effects of Group Response Systems on Student Satisfaction, Learning and Engagement in Accounting Education. Issues in Accounting Education, 22(3), 391-409.

Carnaghan, C. et al. 2011. Using Student Response Systems in the Accounting Classroom: Strengths, Strategies and Limitation. Journal of Accounting Education, 29(4), 265-283.

Filer, D. 2010. Everyone's Answering: Using Technology to Increase Classroom Participation. Nurse Education Perspective, 31(4), 247-250.

Fitch, J. 2004. Student Feedback in the College Classroom: A Technology Solution. Educational Technology Research and Development, 52(1), 71-77.

Florenthal, B. 2018. Students' motivation to participate via mobile technology in the classroom: A uses and gratification approach. Journal of Marketing Education.

Goldstein, D. 2015. Using clickers in the arts and humanities, in Goldstein, D. and Wallis, P. D. (eds.) Clickers in the Classroom: Using Classroom Response Systems to Increase Student Learning. Sterling, Virginia: Stylus Publishing, pp. 35-41. 


\section{CONTINUOUS USE OF STUDENT RESPONSE SYSTEMS IN UNIVERSITY CLASSES: A QUANTITATIVE STUDY OF STUDENT RESPONSE RATES}

Goldstein, D. and Wallis, P. D. (eds.) 2015. Clickers in the Classroom: Using Classroom Response Systems to Increase Student Learning. Sterling, Virginia: Stylus Publishing.

Good, K. C. 2013. Audience response systems in higher education course: A critical review of the literature. International Journal of Instructional Technology and Distance Learning, 10(5), 19-34.

Hunsu, N. et al. 2016. A meta-analysis of the effects of audience response systems (clicker-based technologies) on cognition and affect. Computers \& Education, 94, 102-119.

Jackson, M. et al. 2005. Wireless handheld computers in the undergraduate medical curriculum. Medical Education Online, 10(1), 4386. Doi: 10.3402/meo.v10i.4386

Kay, R. H. and Lesage, A. 2009. Examining the benefits and challenges of using audience response systems: A review of the literature. Computers \& Education, 53, 819-827.

Krabill, R. 2015. Using clickers in the social sciences, in Goldstein, D. and Wallis, P. D. (eds.) Clickers in the Classroom: Using Classroom Response Systems to Increase Student Learning. Sterling, Virginia: Stylus Publishing, pp. 43-52.

Martinez, M. E. 1999. Cognition and the question of test item format. Educational Psychologist, 34(4), 207-218.

Martyn, M. 2007. Clickers in the classroom: An active learning approach. EDUCAUSE Quarterly, 30(2), 71-74.

Narayan, J. et al. 1990. Using Response Cards to Increase Student Participation in an Elementary Classroom. Journal of Applied Behavior Analysis, 23(4), 483-490.

Newland, S. and Black, B. 2019. More than multiple choice: a toolbox for incorporating clickers into political science courses. Journal of Political Science Education. Doi: 10.1080/15512169.2018.1544906

Prince, M. 2004. Does active learning work? A review of the research. Journal of Engineering Education, 93, pp. 223-231.

Premkumar, K. 2009. Rules of engagement - 12 tips for successful use of "clickers" in the classroom. Medical Teacher, 30(2), 146-149.

Robertson, L. J. 2000. Twelve tips for using a computerised interactive audience response system. Medical Teacher, 22(3), 237-239.

Stowell, J. R. and Nelson, J. M. 2007. Benefits of electronic audience response systems on student participation, learning and emotion. Teaching of Psychology, 34(4), 253-258.

Stowell, J. R. et al. 2010. Using student response systems ("Clickers") to combat conformity and shyness. Teaching of Psychology, 37(2), 135-140.

Trees, A. R. and Jackson, M. H. 2007. The Learning Environment in Clicker Classrooms: Student Processes of Learning and Involvement in Large University-level Courses Using Student Response Systems. Learning, Media and Technology, 32(1), 21-40.

Wade, C. H. 2015. When the lesson is in the question: Illuminating research methodology using clickers, in Goldstein, D. and Wallis, P. D. (eds.) Clickers in the Classroom: Using Classroom Response Systems to Increase Student Learning. Sterling, Virginia: Stylus Publishing, pp. 79-93.

Wang, W. et al. 2018. Student Perceptions of Classic and Game-Based Online Student Response Systems. Nurse Educator. Doi: 10.1097/NNE.0000000000000591

Wong, A. et al. 2018. Student perceptions on the use of student response system in higher education in Hong Kong. Proceedings of the 5th Teaching \& Education Conference, Amsterdam, Netherlands, pp. 118-135. 